\title{
A case-note review of continued pregnancies found to be at a high risk of Huntington's disease: considerations for clinical practice
}

\author{
Felicity Wadrup $\mathbb{1}^{1} \cdot$ Simon Holden ${ }^{1,2} \cdot$ Rhona MacLeod $^{3,4} \cdot$ Zosia Miedzybrodzka $^{5,6} \cdot$ Andrea H. Németh $^{7,8}$. \\ Shan Owens $s^{9,10}$. Sara Pasalodos ${ }^{11}$. Oliver Quarrell $\mathbb{D}^{12} \cdot$ Angus J. Clarke $\mathbb{D}^{13} \cdot$ on behalf of the UK \\ Huntington's Disease Predictive Testing Consortium
}

Received: 28 July 2018 / Revised: 17 December 2018 / Accepted: 2 February 2019 / Published online: 19 March 2019

(c) European Society of Human Genetics 2019

\begin{abstract}
Huntington's disease (HD) is a severe neurodegenerative condition that impacts the whole family. Prenatal diagnosis by direct or exclusion testing is available for couples at risk of transmitting HD to their children. An ethical problem can arise after prenatal diagnosis for HD if a known 'high risk' pregnancy is continued to term: international guidelines emphasise that this situation should be avoided where possible, as it removes the resulting child's future right to make an informed, autonomous decision about predictive testing. The UK Huntington's Disease Predictive Testing Consortium recorded 21 pregnancies that were tested, identified as high-risk and then continued. In this qualitative study, health professionals reviewed the case notes of 15 of these pregnancies. This analysis generated guidelines for clinical practice. It is recommended that practitioners: (i) remind couples of the long-term consequences of continuing a high risk pregnancy, (ii) ensure couples understand the information provided, (iii) collaborate closely with other professionals involved in the couple's prenatal care, (iv) prepare couples for the procedural aspects of prenatal diagnosis and a possible termination of pregnancy, (v) allow time for in-depth pre-test counselling, (vi) explain the rationale for only making prenatal diagnosis available subject to conditions, whilst allowing for human ambivalence and acknowledging that these 'conditions' cannot be enforced, (vii) monitor the whole clinical process to ensure that it works 'smoothly', (viii) recommend couples do not disclose the result of the prenatal test to protect the confidentiality and autonomy of the future 'high-risk' child, and (ix) offer on-going contact and support.
\end{abstract}

Supplementary information The online version of this article (https:// doi.org/10.1038/s41431-019-0375-8) contains supplementary material, which is available to authorized users.

Angus J. Clarke

clarkeaj@cardiff.ac.uk

1 East Anglian Medical Genetics Service, Cambridge University Hospitals NHS Foundation Trust, Cambridge, UK

2 Academic Department of Medical Genetics, Addenbrooke's Treatment Centre, Cambridge Biomedical Campus, Cambridge, UK

3 Division of Evolution and Genomic Sciences, School of Biological Science, University of Manchester, Manchester, UK

4 Manchester Centre for Genomic Medicine, St Mary's Hospital, Manchester University Hospitals NHS Foundation Trust, Manchester, UK

5 University of Aberdeen College of Life Sciences and Medicine, Division of Applied Medicine, Aberdeen, UK

6 NHS Grampian Clinical Genetics Service, Medical Genetics,
Aberdeen, UK

7 Oxford Centre for Genomic Medicine, Oxford University Hospitals NHS Foundation Trust, Oxford, UK

8 Nuffield Department of Clinical Neurosciences, University of Oxford, Oxford, UK

9 Hywel Dda UHB (Milford Haven Health Care Centre, Yorke St, Milford Haven, Pembrokeshire, Wales, UK

10 All Wales Medical Genetics Service, University Hospital of Wales, Cardiff, UK

11 Genomic Medicine Unit, Navarrabiomed, Biomedical Research Centre, Pamplona, Spain

12 Department of Clinical Genetics, Sheffield Children's Hospital, OPD II Northern General Hospital, Herries Road, Sheffield, UK

13 Institute of Medical Genetics, University Hospital of Wales, Cardiff, UK 


\section{Introduction}

Huntington's disease (HD), caused by an expanded CAG repeat sequence in exon 1 of the HTT gene [1], is a severe, inherited neurodegenerative condition that results in a progressive decline in motor function and cognitive ability together with a disturbance of affect. The non-motor aspects are often the more disabling for a patient and their family or carers [2-4]. HD is inherited in an autosomal dominant manner and there are a number of reproductive options for couples at risk of transmitting HD: prenatal diagnosis (PND) using chorionic villus sampling or amniocentesis, preimplantation genetic diagnosis, use of donor gametes or embryo, adoption, proceeding to have children while aware of the risks or deciding to remain childless. Non-invasive prenatal diagnosis is also technically possible for some couples although not routinely available in the UK at the time of writing [5].

The two main types of PND are direct testing and exclusion testing [6]. Direct testing involves testing the fetus for the presence or absence of the pathogenic HD variant and gives an accurate result. Exclusion testing uses linkage to test the fetus for the at-risk grandparental haplotype. If the haplotype is absent (i.e., excluded) then the fetus is known to be at low risk of HD whereas presence of that haplotype indicates the fetus is at the same risk as the at-risk parent. Exclusion testing is chosen when the at-risk parent wishes their own status to remain undetermined yet does not wish to have a child at risk of HD. The principal disadvantage of exclusion testing is that the positive predictive value of the test is only $50 \%$ so that, if a pregnancy is terminated on this basis, it is as likely to be unaffected as affected.

One of the most ethically complex issues surrounding PND for HD is the potential for high-risk pregnancies to be continued to term [5,7]. Current international guidelines clearly state that PND is not indicated for couples who would be committed to completing the pregnancy in the event that the fetus is found to be at a high risk [8], although recognising that the decisions made by couples before the test result are somewhat hypothetical. The National Society of Genetic Counsellors argues on those grounds that testing should therefore not be denied a couple, even if they think that they would continue a pregnancy after an increased chance' result [9]. This scenario would result in the child having been tested presymptomatically, thereby preempting his or her right to make an informed, autonomous decision with regards to predictive testing as a mature adult. Several studies have identified a small but significant proportion of tested, high-risk pregnancies that are continued. However, limited information is available on the circumstances surrounding such 'decisions to continue' [10-15]. There is also some limited information about families affected by one of the spinocerebellar ataxias. In brief, eight of 28 Cuban couples continued a high risk SCA2 pregnancy [16] and two of twelve Yakut couples continued high risk SCA1 pregnancies [17].

The UK Huntington's Disease Predictive Testing Consortium (HDPTC) was created in 1989 and collates anonymous data on predictive and prenatal testing for HD across the UK. The HDPTC identified that 21 of 202 highrisk pregnancies were continued [18]. In this qualitative study health professionals reviewed the case notes of 15 of these pregnancies, with the aim to explore the circumstances around their continuation and identify factors that may inform future counselling for couples at risk of HD.

\section{Methods}

\section{Study design}

HDPTC records were reviewed to identify cases from 1988 to 2015 where high risk pregnancies had been continued and where the case notes could be examined. Study design was discussed by the HDPTC and retrospective case note review chosen as the optimum method for this exploratory study as it would maximise the learning from the limited number of cases available. Retrospective case note review is an established method for conducting research in the healthcare setting when the aim is to generate a comprehensive understanding of a complex issue or phenomenon [19].

Neither review by a Research Ethics Committee nor patient consent to the publication of our findings was sought. Research Ethics Committee review is not required for a retrospective review of case notes. It would have been impossible to obtain patient consent and we have fully protected the privacy of the patients and families by removing all identifying information; the clinicians submitting data were acutely alert to the importance of maintaining anonymity. As the case histories have come from two decades and across the UK, it is most unlikely that patient identities could be inferred.

\section{Data collection}

Semi-structured questionnaires for data collection were completed by clinicians from the respective genetics centres. The questionnaire was developed following preliminary review of two cases, peer review, and presentation to members of the HDPTC (Appendix 1). It captured demographic and quantitative data and included free text sections to allow qualitative interpretation of each case history by the reviewing clinician. Two lists of adjectives that could represent a couple's relationship and style of 
decision-making were derived through a discussion among genetics health professionals. Clinicians involved in each case were then asked to select words that represented their assessment of the couple. This design encouraged a focus on the research question whilst allowing flexibility to expand; this "boundary setting" is particularly important for case note reviews [19].

Genetics centres with cases were sent an invitation letter and questionnaire to complete. The letter outlined the purpose of the study and requested data collection by a clinician who had had direct contact with the case wherever possible (Appendix 2). This approach was chosen as it would collate information provided by clinicians who knew the individuals involved and had expertise in this disease [20].

\section{Data analysis}

The demographic and quantitative data were recorded and thematic analysis was used to interpret the answers to the open questions [21]. This involved thorough reading of the questionnaires, recognition of emergent patterns, and generation of common themes. This allowed the identification of features shared between the cases, despite the notes having been written at different times, by different clinicians, about different couples.

\section{Results}

Fifteen questionnaires were returned from ten genetics centres. This represents $71 \%$ of the cases recorded by the
HDPTC where a pregnancy at high risk had been continued. The majority of questionnaires were completed with only minimal omission of information, when it was not available in the clinical notes. Thematic analysis of the qualitative data from the free text sections, in combination with quantifiable information, identified the following themes:

\section{Absence of defining characteristics}

There seemed to be no single defining characteristic shared by all couples that might help identify those likely to continue a high-risk pregnancy. We were unable to compare these 15 cases with the much larger number of cases where the pregnancy was terminated but we could discern no trend in demographic characteristics (Table 1). In eleven cases the at-risk parent was female and in four cases they were male, with the higher proportion of female carriers expected as it reflects that more women than men at risk of HD seek predictive and prenatal testing. Nine had not had predictive genetic testing and were at $50 \%$ risk of $\mathrm{HD}$, and five had received a high-risk positive predictive test result. One parent was displaying symptoms of HD. The age range of the at-risk parent was from 19-41 years, with a mean age of 29 years. In addition, the couples had varying religious beliefs and different reproductive histories. Some of the pregnancies had been planned, but others had not. The couples varied in how long they had known about HD in the family and whether they had received genetic counselling prior to the pregnancy. All but one of the pregnancies were in their first trimester at the point of referral, which is usually the case for couples considering PND. None of the

Table 1 Demographic data of at-risk proband and the pregnancy. (-) denotes information not recorded in clinical notes

\begin{tabular}{|c|c|c|c|c|c|c|c|c|}
\hline Case & $\begin{array}{l}\text { Gender of } \\
\text { at-risk } \\
\text { parent }\end{array}$ & $\begin{array}{l}\text { Age of at- } \\
\text { risk parent } \\
\text { (years) }\end{array}$ & $\begin{array}{l}\text { Risk level of at- } \\
\text { risk parent }(\%)\end{array}$ & $\begin{array}{l}\text { Aware of HD } \\
\text { risk prior to } \\
\text { pregnancy }\end{array}$ & $\begin{array}{l}\text { Contact with } \\
\text { genetics services } \\
\text { prior to pregnancy }\end{array}$ & $\begin{array}{l}\text { First } \\
\text { pregnancy }\end{array}$ & $\begin{array}{l}\text { Pregnancy } \\
\text { planned }\end{array}$ & $\begin{array}{l}\text { Pregnancy } \\
\text { gestation at } \\
\text { referral (weeks) }\end{array}$ \\
\hline 1 & $\mathrm{~F}$ & $40-44$ & 50 & 20 years & $\mathrm{Y}$ & $\mathrm{N}$ & $\mathrm{Y}$ & 5 \\
\hline 2 & $\mathrm{~F}$ & $15-19$ & 50 & many years & $\mathrm{Y}$ & $\mathrm{Y}$ & $\mathrm{N}$ & 8 \\
\hline 3 & M & $25-29$ & symptomatic & many years & $\mathrm{Y}$ & $\mathrm{N}$ & $\mathrm{N}$ & $<12$ \\
\hline 4 & $\mathrm{~F}$ & $30-34$ & 50 & many years & $\mathrm{N}$ & $\mathrm{Y}$ & $\mathrm{N}$ & 4 \\
\hline 5 & M & $30-34$ & 50 & - & $\mathrm{Y}$ & $\mathrm{N}$ & $\mathrm{Y}$ & 6 \\
\hline 6 & $\mathrm{~F}$ & $25-29$ & 50 & yes & $\mathrm{N}$ & $\mathrm{N}$ & - & 15 \\
\hline 7 & $\mathrm{~F}$ & $30-34$ & 50 & yes & $\mathrm{N}$ & $\mathrm{Y}$ & - & 10 \\
\hline 8 & $\mathrm{~F}$ & $25-29$ & 50 & 2 years & $\mathrm{Y}$ & $\mathrm{Y}$ & $\mathrm{Y}$ & 6 \\
\hline 9 & $\mathrm{~F}$ & $25-29$ & 50 & 7 years & $\mathrm{Y}$ & $\mathrm{N}$ & $\mathrm{Y}$ & 7 \\
\hline 10 & $\mathrm{~F}$ & $35-39$ & 50 & 20 years & $\mathrm{Y}$ & $\mathrm{N}$ & $\mathrm{N}$ & 7 \\
\hline 11 & $\mathrm{~F}$ & $25-29$ & 100 & 1 year & $\mathrm{N}$ & $\mathrm{Y}$ & $\mathrm{Y}$ & 4 \\
\hline 12 & M & $30-34$ & 100 & many years & $\mathrm{Y}$ & $\mathrm{Y}$ & $\mathrm{Y}$ & - \\
\hline 13 & $\mathrm{~F}$ & $30-34$ & 100 & 27 years & $\mathrm{Y}$ & $\mathrm{Y}$ & $\mathrm{Y}$ & 9 \\
\hline 14 & M & $25-29$ & 100 & - & $\mathrm{Y}$ & $\mathrm{Y}$ & $\mathrm{N}$ & $<12$ \\
\hline 15 & $\mathrm{~F}$ & $25-29$ & 100 & $>3$ years & $\mathrm{Y}$ & $\mathrm{Y}$ & - & $<10$ \\
\hline
\end{tabular}


couples requested predictive testing in pregnancy prior to PND, a situation associated with additional challenges [22].

\section{Couples were generally close and supportive}

When asked to select the adjectives that best represented each couple's relationship, the clinicians most frequently selected 'long-term', 'committed' and 'loving' (Table 2). Data from the free text supported this view with couples described as 'mutually supportive', 'insightful', and 'in complete agreement with how to proceed'. There were two exceptions; in one case the couple had separated and they differed on whether they would continue the pregnancy if the result was high risk. Indeed, one partner requested a social termination of pregnancy (TOP). In the other, one partner had advanced symptoms of HD contributing to serious social issues that worsened following the pregnancy, as the disease progressed. For eleven of the couples, data were available that showed how long the couples had been in a relationship. Only one couple (described as 'completely devoted') had been together for less than 2 years.

\section{Decision-making was informed yet confused}

Each couple had contact with the clinical genetics team during the pregnancy and prior to the PND procedure (Table 3). These contacts were often numerous, although for one couple the only contact during the pregnancy was by telephone. Most couples were thought to be well informed about the ethical complexities of PND for HD and had expressed explicitly that they would have a TOP in the event of a high-risk result. However, free text data emphasised the difficulties that couples faced in their decision-making once the high-risk result was known. Words representing the couples' decision-making most commonly included 'confused' and 'pressure' (Table 2). In individual cases, factors were identified that added to the difficulties in decision-making, including: a reduced penetrance allele, religious beliefs, discordant views between partners, the inability to face TOP 'for real', increasing attachment to the pregnancy, altered perception of the severity of $\mathrm{HD}$, history of miscarriages and increasing optimism for the future.

\section{Doubt caused by external influences}

There were a number of reports of the couples' decisionmaking being influenced by external factors. In particular, these included interactions with non-genetics health professionals, such as those from fetal medicine or gynaecology departments at the time of chorionic villus sampling (CVS) and TOP. Non-specialist (non-genetics) staff had misunderstandings about the test results, particularly for exclusion testing, and the ethical acceptability of TOP for an adult onset condition was questioned. Thus, one mother was reported as stating that 'a [professional] had told her she would not be allowed to see (the) baby or get photographs' although the notes clearly documented that the process had been explained and extensive counselling provided. Another couple recalled that staff on a gynaecology ward had described the risk to their fetus as 'only a risk'; this changed the couple's perception of the situation. Couples were said to have been influenced by relatives, who had often become aware of pregnancies at the end of the first trimester. This included relatives encouraging and reassuring one couple to continue the pregnancy. Another couple could not face a TOP whilst already experiencing the grief associated with the advancing disease of an affected parent. A further couple reflected on the at-risk parent's own right to life, which had been honoured by their parents despite the risk of HD.

\section{Delays to expected time scales}

It is noteworthy that one third of the 15 couples had experienced unexpected delays at some point during the PND process, although we cannot compare this figure with that for the pregnancies that were terminated. Thus, one couple required a repeat CVS due to inadequate sample at the first attempt, so that they could only access TOP by a medical not surgical procedure. Another couple experienced a delay of 5 days in receiving the results of the PND. A delay in scheduling the TOP procedure in one case meant the TOP could not occur within a timescale acceptable to their religious beliefs. Further delays occurred when couples considered requesting a direct test following a high-risk exclusion test result. The free text data highlighted how these delays may have influenced the decision to continue these pregnancies despite the high-risk result.

\section{Lack of follow up}

About half the couples cut ties with the genetics service despite multiple previous contacts and a seemingly good relationship (Table 4). Many couples did not even inform the department of their decision to continue the pregnancy. One couple 'left the (TOP) ward after discussion with medical staff via (the) fire escape: (they) did not tell staff they were leaving'; another couple chose not to receive the results of a direct test that followed an exclusion test. In general, follow up was limited by couples' decisions following PND.

\section{Telling the children}

The clinical notes generally suggested that couples did not plan to tell their children of their genetic status; however, 


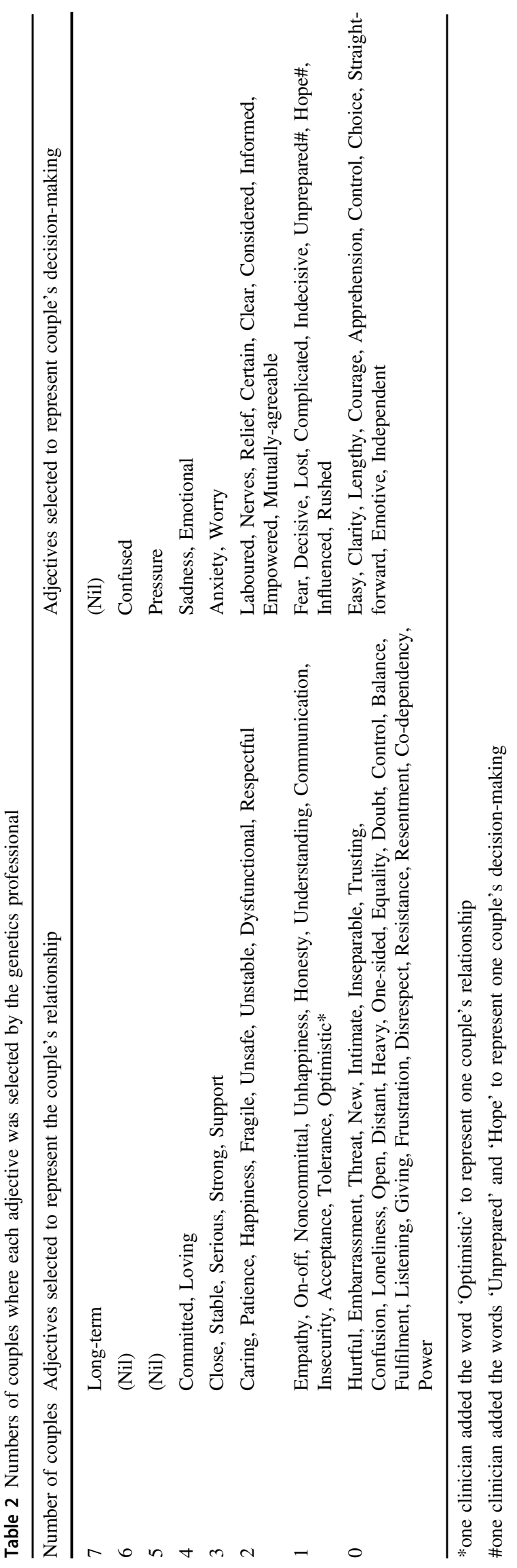

they predicted that the test results would most likely become known. Subsequent predictive testing of the at-risk parent was sought in two cases but performed in only one case, in which the parent recalled the prenatal exclusion test results as 'inconclusive' despite having received a positive test result. In one case, serious social difficulties developed and it was unclear whether the child had been told their prenatal test result.

\section{Discussion}

This is the first study (to our knowledge) to review the clinical case notes of couples undergoing PND for HD and continuing with a high-risk pregnancy. This has identified a number of important considerations for how to deliver optimal care and support for couples considering PND for HD. Although these measures are already widely practised by genetics centres, we hope that proposing them as guidelines might reduce the frequency of predictive information being generated on newborn infants at risk of $\mathrm{HD}$, which occurs following $\sim 10 \%$ of those prenatal diagnoses giving a high-risk result in the UK.

\section{Offer in-depth counselling to all couples}

The results demonstrate the absence of particular characteristics that could alert genetics professionals to those couples that might continue a high-risk pregnancy. For instance, it might be expected that these couples would be less likely to have received pre-conception genetic counselling, which is recognised as important to allow couples time to consider all available options, make informed decisions, and avoid simultaneous predictive and prenatal testing [8]. However, eleven couples did have contact with genetics services prior to the pregnancy. A larger proportion of unplanned pregnancies might also be expected in this cohort [5], yet around half of the pregnancies were planned. Similarly, 'young' couples have been predicted to be more likely to continue a high-risk pregnancy due to increased uncertainty [22], but there was a wide age range in our data set. Interestingly, a recent study in France found that reproductive decisions in HD are made afresh with each pregnancy, which reflects our findings [23]. A conflict-prone or troubled relationship might also be anticipated more often in these couples but, contrary to this, 13 of the couples' relationships were perceived to be close and supportive. Decruyenaere et al. [12] also found agreement between spouses in decision-making for reproductive choice in HD, and Bouchghoul et al. [23] found no significant impact of the outcome of PND for HD on couples' relationship status over time. 
Table 3 Decision-making data. (-) denotes information not recorded in clinical notes

\begin{tabular}{lllll}
\hline Case & $\begin{array}{l}\text { Contacts with genetics } \\
\text { services in pregnancy }\end{array}$ & $\begin{array}{l}\text { Clinician view of } \\
\text { couples' understanding }\end{array}$ & $\begin{array}{l}\text { Exclusion (E) or } \\
\text { direct (D) testing of } \\
\text { fetus }\end{array}$ & $\begin{array}{l}\text { Couple explicit they } \\
\text { would have TOP if high } \\
\text { risk result }\end{array}$ \\
\hline 1 & phone/CVS & mixed & E & Y \\
2 & clinic/phone/CVS & rushed/confused & E & discordant \\
3 & several meetings & very good & D & Y \\
4 & clinic/phone/CVS & good & E & Y \\
5 & clinic/phone & clear & E & Y \\
6 & clinic/phone & good & E then D & Y \\
7 & clinic/phone & good & E & - \\
8 & several meetings & complete & E & Y \\
9 & several meetings & complete & E & Y \\
10 & clinic/phone & complete & E & Y \\
11 & clinic/phone/CVS & good & D & Y \\
12 & - & - & D & Y \\
13 & clinic/phone & - & D & Y \\
14 & clinic/phone & understood & D & Y \\
15 & phone & - & D & - \\
\hline
\end{tabular}

Table 4 Follow up data. (-) denotes information not recorded in clinical notes and (n/a) denotes not applicable

\begin{tabular}{lllll}
\hline Case & $\begin{array}{l}\text { The stage } \\
\text { couple } \\
\text { declined } \\
\text { TOP }\end{array}$ & $\begin{array}{l}\text { Did couple } \\
\text { inform } \\
\text { department of } \\
\text { decision to } \\
\text { continue } \\
\text { pregnancy }\end{array}$ & $\begin{array}{l}\text { Further } \\
\text { contact with } \\
\text { genetic } \\
\text { services after } \\
\text { the pregnancy }\end{array}$ & $\begin{array}{l}\text { Attended for } \\
\text { future } \\
\text { predictive test } \\
\text { (cases of } \\
\text { exclusion } \\
\text { testing) }\end{array}$ \\
\hline 1 & after result & Y & N & N \\
2 & after CVS & Y & Y & Y \\
3 & after result & N & Y & n/a \\
4 & after result & Y & Y & N \\
5 & after result & Y & Y & N \\
6 & after result & N & N & n/a \\
7 & - & Y & Y & Y \\
8 & day of TOP & N & N & N \\
9 & day of TOP & N & Y & N \\
10 & day of TOP & N & Y & N \\
11 & after result & Y & Y & n/a \\
12 & after result & - & N & n/a \\
13 & after result & Y & N & n/a \\
14 & after result & Y & N & n/a \\
15 & after result & N & N & n/a \\
\hline
\end{tabular}

Prenatal testing for HD requires high quality counselling by a fully informed professional $[8,12]$. We were unable to recognise any clear indicators to predict which couples would continue a high-risk pregnancy. This suggests the need for professionals to emphasise the complex and long- term ethical consequences of continuing a pregnancy at high risk to every couple considering prenatal diagnosis, whether before or during an ongoing pregnancy. However, the case studies reported here do not indicate any lack of such information or counselling support. It is likely that couples will change their minds about a TOP in the face of a high-risk result despite the very best genetic counselling practice. We must accept that humans experience ambivalence in difficult circumstances and we should resist any inclination to blame either the couples or the professionals involved.

\section{Evaluate couples' comprehension}

The couples' decision-making was described by the clinicians as informed yet confused. Studies demonstrate that couples have great difficulty in grasping certain concepts during prenatal counselling for $\mathrm{HD}$, particularly relating to exclusion testing, with up to $90 \%$ of couples requiring repeated explanation [24, 25]. This study found that comprehensive information had been provided, although retrospective assessment of the couples' understanding and information retention is not available. Irrespective of the patients' educational backgrounds, it is crucial that genetics professionals ensure that couples understand the information provided and that the issue of TOP is addressed directly [25]. We therefore suggest prenatal counselling should routinely include strategies actively to evaluate couples' understandings, particularly around exclusion testing, the possibility of 'grey area' results and the ethical implications of continuing a likely affected pregnancy. Detailed technical 
information is perhaps less important than helping couples to appreciate the potential implications of each of the possible test results and pregnancy outcomes for their own unique set of personal circumstances. The greater attention sometimes paid in prenatal genetic counselling to the provision of information as opposed to the salient counselling issues has been noted before [26]. Highlighting and rehearsing information recall under the immense pressure couples will experience following the CVS result may also be beneficial.

\section{Educate other healthcare providers, especially those involved in managing a pregnancy}

Feelings of confusion and uncertainty during the decisionmaking process in PND for HD have been recognised before [24]. Conflicting messages from sources external to the genetics services contributed to the confusion in the making of decisions. Some couples were apparently influenced by the opinions of their relatives, who had often become aware of the ongoing pregnancy by the end of the first trimester and encouraged couples to continue. The impact of relatives' views on reproductive choice in families with HD has been recognised [27]. However, more numerous and notable were the instances of confusion triggered by information from non-genetics health professionals. This was usually from staff in fetal medicine or gynaecology units at the time of the CVS or TOP.

It is critically important that health professionals from all disciplines involved in reproductive care provide accurate information and clear advice that is consistent with the input provided in genetic counselling [28]. However, in the cases we report, misunderstandings and mixed messages about the meaning of results seem to have arisen among the nongenetics professionals, particularly about exclusion testing and the ethics of TOP for an adult onset condition. At a time when couples often form a stronger attachment to their pregnancy, and when their decision-making is already highly pressured, couples may have been particularly influenced by these messages conflicting with their previous decisions. The mixed messages to which they were exposed may have been pivotal in how these couples chose to proceed.

We wish to highlight the importance of the education of non-genetics health professionals about the unique features of PND for HD. Effective multidisciplinary team working and communication with the couple's primary care team and midwife/obstetrician should be maintained to provide the maximum support. Standard good practice should include copying correspondence to all relevant health professionals. This unique scenario may also benefit from a face-to-face discussion between the midwife, obstetrician and genetic counsellor. The prenatal genetic counselling process might also forewarn couples about the potential for misunderstanding by other professionals and suggest taking genetics summary letters to hospital appointments.

\section{Prepare couples for the reality of the process of PND and termination of pregnancy}

Part of preparing couples for PND is establishing a defined timeline of events, often including set dates for an ultrasound dating scan, the CVS procedure, and the delivery of results. It is also known that waiting for the results of PND is difficult and distressing [23, 29], and that support with the practical arrangements for a TOP following unfavourable results is very important [24]. A number of couples in this cohort experienced delays during the PND process, which were thought to have contributed to their decisions to continue their pregnancies. CVS testing is usually conducted at around 12 weeks gestation, a time when couples often have their first ultrasound scan, develop a stronger bond with the pregnancy and inform family members about it [30]. Delays of even a few days may dramatically alter how couples feel towards the pregnancy, with evidence suggesting couples might suddenly feel a new level of attachment as bonding increases with gestation [31]. Indeed, seeing the ultrasound image of the fetus has been recorded as the reason one couple chose to continue a high risk pregnancy [32]. For several couples, the procedural delays, added to an already pressured decision-making process, may have disrupted their rehearsed schedule of events and meant that they found it even harder to bear the prospect of terminating an otherwise wanted pregnancy. Whilst there is an inevitable progression to pregnancy, efforts can be made to ensure couples are prepared for the reality of the procedure, the possibility of delays and the emergence of a new level of attachment to the pregnancy. There is a paucity of literature evaluating coping mechanisms in women undergoing PND [33], however coping strategies for this group can be discussed and might include (i) a decision as to whether to view the ultrasound image at CVS, (ii) consideration of whether they disclose details of their pregnancy to relatives, and (iii) forewarning genetics laboratories and fetal medicine teams of the upcoming PND test. Every effort should be made to avoid delays. Another important area is the continued education for genetics professionals on the principles of caring for women undergoing prenatal procedures [29]. Genetics professionals are well versed in the ethical and genetic counselling aspects of PND for HD. However, their experience of the procedural aspects of PND and their impact on couples may be limited, yet this seems crucial in the preparation of couples who plan to proceed with PND and, perhaps, a TOP. 


\section{Support complex decision-making}

The results describe the range of factors that were identified as compounding the difficulties of couples' decisionmaking. Notably, one couple received a high-risk result on a prenatal exclusion test. They opted for direct testing but then chose not to receive the result. This could represent the avoidance of possible 'double bad news' where the fetus and at-risk parent are diagnosed simultaneously [25, 34].

We were unable to capture enough detail in this review to evaluate each factor individually. Cumulatively, however, these case histories highlight the complexity of the couples' decision-making. Additional influences on decision-making for couples who have continued a high risk pregnancy include outcomes from previous PND [23], doubting the at-risk parent's predictive test result [24], TOP for a pregnancy at 50\% risk in the case of exclusion testing [10], ambivalence, and cognitive decline or emotional lability in the at-risk parent as a result of HD [32]. There is also the suggestion that, when couples discover their fetus has a smaller CAG repeat size than the affected parent, albeit still pathogenic, this may nurture their sense of hope for the future [14]. Increasing access to social media and the internet, and the introduction of new prenatal testing procedures such as non-invasive prenatal diagnosis, may further complicate reproductive decision-making $[5,28]$. New technologies may also exacerbate the so-called 'technological imperative' facing couples [12, 24]. The range of factors influencing couples' reproductive decision-making after genetic counselling has been reviewed [28]. Genetics professionals must allow time, including additional clinic appointments if needed, for in-depth, pre-test counselling.

\section{Empower couples to access support in the long-term}

There was limited information in the clinic notes about the ongoing impact of each couple's decision on the child and the family as a whole. Indeed, many couples appear to have consciously disengaged from genetics services, despite regular prior contact and a seemingly good relationship. We speculate they may have felt apprehensive about disclosing their decision as it was contrary to the previously expressed and agreed course of action. While current international guidelines recommend that access to PND for those at risk of transmitting HD be conditional upon agreement to terminate a high-risk pregnancy, these guidelines do not overrule a couple's - or the woman's - entitlement to change their mind after receiving the test result [5, 7-9].

The high-risk result for each of these pregnancies is known by at least the couple and a number of health professionals, thus the future child's right to confidentiality over his or her genetic status has been breached, as has, most probably, their ability to make an informed, autonomous decision with regards to predictive testing as a mature adult. To limit the extent of this breach, we recommend that couples are counselled to not disclose the results of the PND to relatives or friends. The likely burden on couples of carrying this information in isolation presents another compelling reason to empower couples to access support in the long-term.

\section{Summary and conclusion}

Genetic counselling for PND in HD is a challenging balance between offering non-directive support to couples in making an informed choice, versus the offer of PND being presented and understood as, in effect, conditional upon an agreement to terminate a high-risk pregnancy. Achieving an understanding with couples that acknowledges the rationale for PND whilst also conveying impartiality and a recognition of human ambivalence seems key to maintaining longterm contact. Genetics professionals invest much time and effort counselling couples in this scenario and are skilled in supporting families at risk of HD. Given the abrupt termination of contact by couples when they continue their highrisk pregnancies, the professionals involved may feel that they failed in their counselling and they could be left with concerns about how the situation might evolve for the families. This remains an important area for further research.

Further studies investigating the long-term impact of continued high-risk pregnancies on families are crucial if genetics professionals are to learn how best to support families both at the time of PND and as the situation evolves over time. There is very limited literature addressing this issue, presumably as this situation arises infrequently and there is a lack of follow up information. Recently Bouchghoul et al. [23] examined whether children are informed about their genetic status following PND for $\mathrm{HD}$ and report one case of a continued pregnancy at high risk. The carrier mother in this instance had not disclosed the result to her then 9 year-old child; the usual age of disclosure for those children with a negative HD test prenatally was 10-18 years. Psychological support following PND for HD, especially following a bad news result, is imperative [23] and recommendations for predictive testing in HD reiterate the importance of follow up [8]. Therefore, until there is specific evidence for how best to support couples that have continued a high-risk pregnancy, we suggest genetic services make every effort to continue to offer on-going contact. Couples considering PND are routinely signposted to additional support options, such as the Huntington Disease Association, and these may serve as alternatives for couples that decline on-going support. 


\section{Summary of guidelines for clinical practice}

i. Before the diagnostic procedure, remind every couple of the complex and long-term ethical consequences of continuing a pregnancy at high risk of HD.

ii. Help couples to understand the information provided, evaluate their understanding as part of the counselling process, and rehearse their recall in the scenario of a high-risk result.

iii. Educate other health professionals about the exceptional circumstances of PND for HD and ensure good multidisciplinary team working.

iv. Prepare couples for the reality of the PND and TOP procedures; discuss and rehearse coping strategies.

v. Allow sufficient time for in-depth pre-test counselling, given the complexity of these decisions.

vi. Explain the rationale for the offer of PND being made conditional upon a commitment to terminate the pregnancy if the test gives a high-risk result, whilst allowing for human ambivalence.

vii. Monitor the whole process of diagnostic procedure, laboratory analysis, return of results and organisation of TOP to ensure it works without delays or confusions.

viii. Recommend that couples do not disclose the result of the prenatal test, so as to protect the confidentiality and autonomy of the future child.

ix. Make every effort to offer on-going contact and support to couples.

\section{Strengths and limitations}

A strength of this study is that data were obtained from the case-notes of a substantial proportion of all UK recorded cases where pregnancies known to be at high risk of HD have been continued. Furthermore, the clinicians who completed the questionnaires were all genetics professionals with a specialist interest in HD who were, therefore, well placed to provide relevant and insightful responses. Conversely, the fact that the professionals were drawn from different locations may be seen as a limitation of the study. The retrospective design, the necessity for potentially identifying data to be omitted, and the lack of detail in some case notes were further limitations. Our inability to compare these 15 cases with those where increased risk pregnancies were terminated prevents us from making systematic comparisons between those cases where pregnancies were and were not terminated. Finally, the lack of follow up contact with couples results in the outcomes for many couples remaining unclear. Many of these limitations would be mitigated if data collection in the future is prospective; this would entail collecting data on all pregnancies subject to prenatal testing for HD.

Acknowledgements Alan Fryer, Cheshire and Merseyside Clinical Genetics Service, Liverpool Women's NHS Foundation Trust, Liverpool, UK. Brain Smith, West of Scotland Regional Genetics Service, Southern General Hospital, Glasgow, UK. Elizabeth Rosser, NE Thames Regional Genetics Service, Great Ormond St Hospital, London, WC1N 3EH. Bernadette Farren, NE Thames Regional Genetics Service, Great Ormond St Hospital, London, WC1N 3EH. Mary O'Driscoll, West Midlands Regional Clinical Genetics Service, Birmingham Women's Hospital NHS Foundation Trust. Christopher Platt, West Midlands Regional Clinical Genetics Service, Birmingham Women's Hospital NHS Foundation Trust. Diana Scotcher, Manchester Centre for Genomic Medicine, St Mary's Hospital, Manchester.

\section{Compliance with ethical standards}

Conflict of interest The authors declare that they have no conflict of interest.

Publisher's note: Springer Nature remains neutral with regard to jurisdictional claims in published maps and institutional affiliations.

\section{References}

1. A novel gene containing a trinucleotide repeat that is expanded and unstable on Huntington's disease chromosomes. The Huntington's Disease Collaborative Research Group. Cell. 1993;72: 971-83.

2. Novak MJ, Tabrizi SJ. Huntington's disease. BMJ. 2010;340: c3109.

3. Roos RA. Huntington's disease: a clinical review. Orphanet J Rare Dis. 2010;5:40.

4. Bates GE, Tabrizi SE, Jones LE, (eds). Huntington's disease. 4th edn. Oxford, UK: Oxford University Press; 2014.

5. de Die-Smulders CE, de Wert GM, Liebaers I, Tibben A, EversKiebooms G. Reproductive options for prospective parents in families with Huntington's disease: clinical, psychological and ethical reflections. Hum Reprod Update. 2013;19:304-15.

6. Harper PS, Sarfarazi M. Genetic prediction and family structure in Huntington's chorea. Br Med J. 1985;290:1929-31.

7. Duncan RE, Foddy B, Delatycki MB. Refusing to provide a prenatal test: can it ever be ethical? BMJ. 2006;333:1066-8.

8. MacLeod R, Tibben A, Frontali M, et al. Recommendations for the predictive genetic test in Huntington's disease. Clin Genet. 2013;83:221-31.

9. Hercher L, Uhlmann WR, Hoffman EP, Gustafson S, Chen KM, the Public Policy Committee of NSGC. Prenatal testing for adultonset conditions: the position of the National Society of Genetic Counselors. J Genet Couns. 2016;25:1139-45. https://doi.org/10. 1007/s10897-016-9992-3

10. Simpson SA, Zoeteweij MW, Nys K, et al. Prenatal testing for Huntington's disease: a European collaborative study. Eur J Hum Genet. 2002;10:689-93.

11. Creighton S, Almqvist EW, MacGregor D, et al. Predictive, pre-natal and diagnostic genetic testing for Huntington's disease: the experience in Canada from 1987 to 2000. Clin Genet. 2003;63:462-75.

12. Decruyenaere M, Evers-Kiebooms G, Boogaerts A, et al. The complexity of reproductive decision-making in asymptomatic carriers of the Huntington mutation. Eur J Hum Genet. 2007;15:453-62. 
13. Tolmie JL, Davidson HR, May HM, McIntosh K, Paterson JS, Smith B. The prenatal exclusion test for Huntington's disease: experience in the west of Scotland, 1986-1993. J Med Genet. 1995;32:97-101.

14. van Rij MC, de Koning Gans PA, Aalfs CM, et al. Prenatal testing for Huntington's disease in the Netherlands from 1998 to 2008. Clin Genet. 2014;85:78-86.

15. Laccone F, Engel U, Holinski-Feder E, et al. DNA analysis of Huntington's disease: five years of experience in Germany, Austria and Switzerland. Neurology. 1999;53:801-6.

16. Cruz-Mariño T, Velázquez-Pérez L, González-Zaldivar Y, Aguilera-Rodríguez R, Velázquez-Santos M, Vázquez-Mojena Y, et al. Couples at risk for spinocerebellar ataxia type 2: the Cuban prenatal diagnosis experience. J Community Genet. 2013;4:45160. https://doi.org/10.1007/s12687-013-0147-z

17. Kononova SK, Sidorova OG, Fedorova SA, Platonov FA, Izhevskaya VL, Khusnutdinova EK. Bioethical issues of preventing hereditary diseases with late onset in the Sakha Republic (Yakutia). Int J Circumpolar Health. 2014;73:25062 https://doi. org/10.3402/ijch.v73.25062

18. Piña-Aguilar RE, Simpson SA, Alshatti A, Clarke A, Craufurd D, Dorkins $\mathrm{H}$, et al. 27 years of prenatal diagnosis for Huntington disease in the United Kingdom. Genetics in Medicine. 2018. https://doi.org/10.1038/s41436-018-0367-z. [Epub ahead of print].

19. Crowe S, Cresswell K, Robertson A, Huby G, Avery A, Sheikh A. The case study approach. BMC Med Res Methodol. 2011;11:100.

20. Palinkas LA, Horwitz SM, Green CA, Wisdom JP, Duan N, Hoagwood K. Purposeful sampling for qualitative data collection and analysis in mixed method implementation research. Adm Policy Ment Health. 2015;42:533-44.

21. Boyatzis RE. Transforming qualitative information: thematic analysis and code development. Thousand Oaks, CA; London: Sage Publications; 1998

22. Lesca G, Goizet C, Dürr A. Predictive testing in the context of pregnancy: experience in Huntington disease and autosomal dominant cerebellar ataxia. J Med Genet. 2002;39:522-5.
23. Bouchghoul H, Clément SF, Vauthier D, et al. Prenatal testing in Huntington disease: after the test, choices recommence. Eur J Hum Genet. 2016;24:1535-40.

24. Adam S, Wiggins S, Whyte $P$, et al. Five year study of prenatal testing for Huntington's disease: demand, attitudes, and psychological assessment. J Med Genet. 1993;30:549-56.

25. Tyler A, Quarrell OW, Lazarou LP, Meredith AL, Harper PS. Exclusion testing in pregnancy for Huntington's disease. J Med Genet. 1990;27:488-95.

26. Hodgson JM, Gillam LH, Sahhar MA, Metcalfe SA. Testing times, challenging choices: an Australian study of prenatal genetic counseling. J Genet Couns. 2010;19:22-37.

27. Downing C. Negotiating responsibility: case studies of reproductive decision-making and prenatal genetic testing in families facing Huntington disease. J Genet Couns. 2005;14:219-34.

28. Pergament E, Pergament D. Reproductive decisions after fetal genetic counselling. Best Pract Res Clin Obstet Gynaecol. 2012;26:517-29.

29. Chescheir NC, Cefalo RC. Prenatal diagnosis and caring. Women's Health Issues. 1992;2:123-32.

30. Øyen L, Aune I. Viewing the unborn child-pregnant women's expectations, attitudes and experiences regarding fetal ultrasound examination. Sex Reprod Healthc. 2016;7:8-13.

31. Rossen L, Hutchinson D, Wilson J, et al. Maternal bonding through pregnancy and postnatal: findings from an Australian Longitudinal Study. Am J Perinat. 2017;34:808-17.

32. Wedderburn S, Panegyres PK, Andrew S, et al. Predictive gene testing for Huntington disease and other neurodegenerative disorders. Intern Med J. 2013;43:1272-9.

33. Nakić Radoš S, Košec V, Gall V. The psychological effects of prenatal diagnostic procedures: maternal anxiety before and after invasive and noninvasive procedures. Prenat Diagn. 2013;33:1194-200.

34. van Rij MC, de Koning Gans PA, van Belzen MJ, et al. The uptake and outcome of prenatal and pre-implantation genetic diagnosis for Huntington's disease in the Netherlands (19982008). Clin Genet. 2014;85:87-95. 